\title{
Homeopathy for Past Birth Trauma
}

\section{Opinion}

Since working with mothers and children in homeopathy, I've come across a large group of people that have experienced birth trauma, either as the mother or child. Often what affects one will affect the other. In her book, Origins, Annie Paul describes monitoring of the pregnant mothers' physical bodies at rest (via headphones and eye covers) and their childs' affect on their mothers when they startle the babies externally with noise. The mothers' body shows the spike in biological markers to the fetus' response. So not only do we affect our unborn, but they, in turn, affect us. Of course when I read this, I immediately remembered all those mornings after masters' swim class, driving in the car, belting out my rendition of all Phil Collins' latest. Thank goodness he has no memory of it, but I'm sure I've scarred him somehow. It must have been his revenge, all those evenings with his extremities rambling over my extended belly months later. Pregnancy should be a happy time, a time for the mother to be cared for and loved; it becomes evident that as society stresses the pregnant woman, the child does not grow to her full potential. Ms. Paul tells us that those exposed to stressors such as starvation early in the pregnancy are more prone to heart disease, whereas those later in pregnancy, diabetes is the disease seen.

When a mother brings a child into my office with a specific set of symptoms, I may see that the child's rubrics, the symptoms that are presented by the child's vital force, call for a trauma remedy. Sometimes I'll see two within the first 3 or 4 remedies represented. Once I remember calling the mother back, and questioning her further, 'Are you sure there wasn't some birth trauma, or maybe in utero?' The mother finally admitted the father never wanted the child, and wouldn't speak to the mother for 6 months. The traumatized mother shared this wound with her baby. The choice of a remedy is not a subjective decision, rather the symptoms exhibited by this new life; its way to show there is an imbalance. If this imbalance is not corrected, it will possibly grow worse. But it will assuredly affect the child, and as a mild problem is not treated, it may grow to a more serious one. Stresses are normal for the human population; they encourage adaptation to our surroundings. But at a certain point, they drag down the vital force, and the child cannot stretch free of what holds its vital force down. We all want to see children that are happy and healthy and chronic illness may result from birth trauma, and not just in the children. I've seen mothers benefit from a high dose of Arnica after almost 10 years.

In such intimate circumstances, one would imagine that even if you had just delivered your child, you would still be traumatized by the sight of your newborn's blue pallor from a cord around its tender neck. Thus both mother and child would suffer the trauma, but with different results; the mother may need Arnica or Aconite, the child may need Opium or Phosphorus. Annie Paul's message is to take better care of the pregnant women. I'm all for that! See your homeopath today to clear away those traumas, physical,

\begin{tabular}{l} 
Volume 7 Issue 2 - 2017 \\
Renita Herrmann* \\
San Francisco Community Group, USA \\
*Corresponding author: Renita Herrmann, San Francisco \\
Community Group, 221 El Camino Del Mar, San Francisco, CA \\
94121, USA, Email: renitaherrmann@ @gmail.com \\
Received: March 28, 2017 | Published: May 30, 2017 \\
\hline
\end{tabular}

mental, and emotional, to have that bouncing baby reach her full potential! And read the book, it's very engaging.
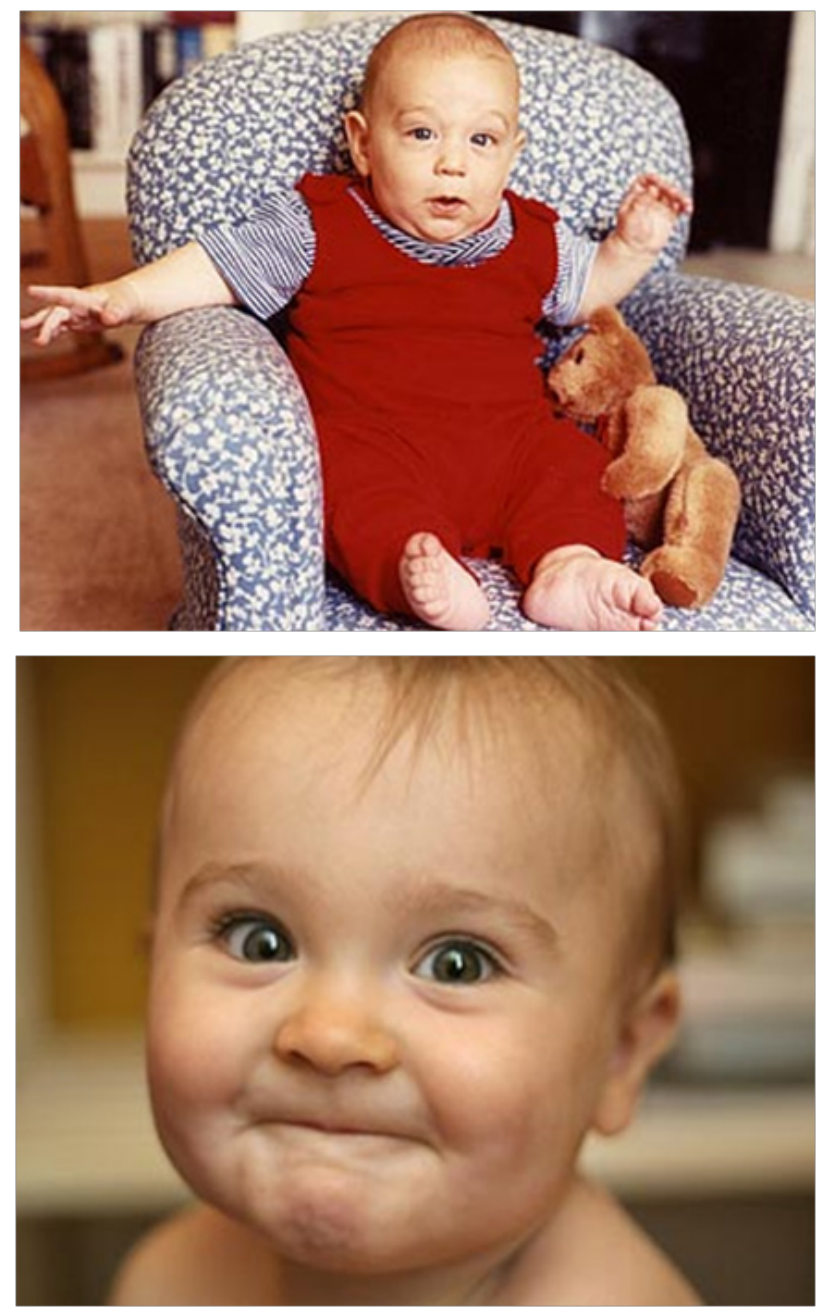